\title{
O CENÁRIO DO USO DAS TECNOLOGIAS NA ESCOLA DO SÉCULO XXI
}

\author{
Vanessa C. Marinho \\ Colégio Pedro II \\ Campo de São Cristóvão 177 - $3^{\circ}$ andar - São Cristóvão -20921-903 - Rio de Janeiro - \\ RJ - Brazil \\ Laboratório de Informática Educativa \\ vanessacp2@gmail.com

\begin{abstract}
The concern of this article focuses on the demands of the professional profile of the teacher who has the responsibility to contribute to the education of citizens attentive to changes in the world, teaching them to be lifelong learners. Information technology - IT gave plural treatment to information, conveying it dynamically to serve varied purposes, including to education. However, despite the investment to equip schools with computers and other technological devices, the practice continues formatted didactic methods antiquated, far from the reality of the generation born in the age of cyberculture.
\end{abstract}

RESUMO. A preocupação deste artigo concentra-se na demanda do perfil profissional do professor, que tem a responsabilidade de contribuir na formação de cidadãos atentos às transformações do mundo, ensinando-os a serem aprendizes permanentes. As tecnologias da informação - TI deram um tratamento plural à informação, veiculando-a de forma dinâmica para servir a variados fins, inclusive à educação. Entretanto, apesar do investimento para dotar as escolas de computadores e demais aparatos tecnológicos, a prática didática continua formatada em metodologias antiquadas, distante da realidade da geração nascida na era da cibercultura. 


\section{Introdução}

O trinômio tecnologia-informação-comunicação (TIC) tornou-se vital à subsistência e ao desenvolvimento da humanidade e o conhecimento produzido, distribuído e apreendido por meio deste trinômio precisa ser compartilhado, a fim de trazer algum equilíbrio às relações sociais, demarcadas pelas desigualdades socioeconômicas. A presença da TIC no mundo contemporâneo faz reaparecer com intensidade a temática da Educação como elemento diferenciador e indicador de desenvolvimento dos cidadãos e da sociedade.

A Educação se viu, então, forçada a repensar seus fundamentos, procedimentos e objetivos e, nesse contexto, as políticas nacionais incorporaram a necessidade de implantar a informática nas escolas, em especial, do ensino fundamental e médio, com a expectativa de ampliar aos alunos o acesso democrático às informações complementares aos núcleos curriculares especializados, segundo as prerrogativas da moderna sociedade digital.

Pode-se dizer que o projeto EDUCOM ${ }^{1}$, elaborado e implementado na passagem dos anos 80 para os 90, foi o marco da Informática Educativa no Brasil e, como muitas ações governamentais, foi desenhado para atender as escolas públicas em larga escala, mas estruturado para realizar pouco. $\mathrm{O}$ caráter dessa proposta era (e precisava ser) interdisciplinar, pois, entre outros motivos, não havia número suficiente de profissionais da Educação para implantar centros-piloto, para capacitar educadores e levar a cultura do uso do computador como recurso auxiliar de aprendizagem a todos os graus e modalidades de ensino do país (ANDRADE, 2002; MORAES, 1997). O momento atual exibe a presença vigorosa de equipamentos de informática no ambiente escolar, mas com desproporcionalidade de uso na aprendizagem, traduzida por Area (In SANCHO\&HERNÁNDEZ, 2008) como

[...] interesse em submeter a formação escolar às necessidades da economia e do mercado, em detrimento de um modelo de escolaridade que procurava, em décadas passadas, a democratização e a igualdade social. Por isso, a justificativa da introdução das novas tecnologias em aula está apoiada em três condições básicas, pois: convertem as escolas em espaços mais eficientes e produtivos; conectam a formação com as necessidades da vida social e preparam os alunos para a atividade profissional do futuro (p. 154).

Com efeito, a subutilização dos recursos dos computadores e seus periféricos nos planos didáticos parece não ocorrer isoladamente em uma escola, ou em um país, constituindo o principal objetivo da investigação aqui apresentada, que tem como objeto de campo uma tradicional instituição pública básica e tecnológica, atendendo a mais de 12 mil alunos distribuídos em 14 campi equipados com TVs, projetores multimídia para serem usados nas salas de aula regular, laboratórios de informática, com, pelo menos, um

\footnotetext{
${ }^{1}$ Proposta interdisciplinar governamental, consolidada em 1983, voltada à implantação experimental de centros-piloto como infraestruturas relevantes para o desenvolvimento de pesquisas, objetivando a capacitação nacional e coleta de subsídios para uma futura política setorial. (MORAES, 1997)
} 
professor especialista em cada um deles, e, mais recentemente, um tablet para cada professor regente. Na implantação desses laboratórios, ao final da década de 80 , foram oferecidos vários cursos de capacitação internos e externos por quase 10 anos. O quadro docente tem formação acadêmica relevante, mas curiosamente refratário ao uso da tecnologia no cotidiano escolar.

Molin e Raabe (2012) também tiveram constatado em sua pesquisa "que o número de professores que usam o computador nas atividades com os alunos é ainda pequeno e este uso se restringe aos laboratórios de informática das escolas". Então, em que medida os programas de capacitação de professores nos recursos da informática contribuem para qualificar os profissionais e engajar, efetivamente, esta tecnologia à prática didática? Por que o investimento no desenvolvimento da educação básica não inclui a capacidade tecnológica deste profissional?

Acredita-se que a busca pelas respostas a estes questionamentos pode ser amparada por um processo de coleta de dados particulares, suficientemente constatados, para inferir uma verdade geral ou universal. Tal processo é formalmente classificado como método indutivo, a ser realizado em três etapas: (1) observação do fenômeno; (2) análise do perfil dos envolvidos e do ambiente; (3) considerações das causas que impedem que a maioria dos professores não use a tecnologia integrada à sua prática didática neste segmento e apresentação de sugestões de ações.

Para Delacôte (apud Catasús, 1996) a atualidade está assistindo à eclosão de três revoluções que podem modificar a forma de aprender e seus sistemas de gestão. São eles: (1) a revolução da interatividade (apoiada pelas novas tecnologias - como os produtos de multimídia e a internet - com seu grande potencial pedagógico); (2) a revolução da psicologia cognitiva (o campo do processo de ensino-aprendizagem apoiado pelas novas tecnologias, possibilitando novas estratégias didáticas de construção de conhecimento); e, (3) a revolução de gestão do sistema educativo (diante do emergente contexto social e econômico, do ambiente multicultural que o caracteriza e do desenvolvimento das tecnologias da informação e comunicação, a escola não pode ser considerada o único espaço de aprendizagem). Estes movimentos desenham um novo perfil profissional do educador e configura novas possibilidades de ensinar e aprender.

De toda maneira, a expansão telemática vem combinando cada vez mais a comunicação de massa à interatividade, fazendo com que a articulação dos indivíduos seja recíproca tanto local quanto global. A topologia da comunicação em rede, característica da Internet, iniciada com o correio eletrônico (e-mail), alargou, em pouco tempo, suas opções em listas, fóruns, blogs, facebook, salas virtuais, teleconferências e outros mais, disponíveis a muitos fins, inclusive educacionais. Por isso, o objetivo desta pesquisa, ainda em andamento, é identificar meios e processos que possam assegurar que a TIC seja definitivamente integrada à prática didática na escola básica.

\section{O aluno no século XXI}

O Brasil vem empregando esforços a fim de obter uma posição economicamente estável em meio às grandes potências mundiais, e para que este objetivo seja alcançado é preciso fortalecer seus direitos de cidadania, reconhecendo sua própria cultura, 
fomentando seu conhecimento e criatividade, e isto só poderá ser conquistado por meio de investimentos maiores e inovadores em Educação.

Segundo pesquisa do Ibope divulgada pela impressa em junho de 2012, 82,4 milhões de brasileiros têm acesso à rede mundial internet, superando em $5 \%$ o número de usuários do ano anterior. A pesquisa leva em conta o acesso à internet de todos os ambientes, seja em casa, no trabalho, nas escolas ou em lan houses. Deste quantitativo, cerca de $80 \%$, equivalente a 66 milhões de pessoas, acessam a web em seus domicílios ou locais de trabalho. A invasão do computador em diferentes segmentos da sociedade, incluídas as instituições de ensino, seguida pela internet, detonou todo um processo que incentiva novas relações com o multicultural, com o ensinar e o aprender, com o acesso/seleção de um mundo de informações advindas de uma grande rede virtual. Por isso, é importante entender este processo de transformação como uma questão também cultural e não especificamente tecnológica (PRETTO, 2001).

A viabilidade e eficácia da TIC nos processos de aprendizagem dos alunos depende, principalmente, dentre outros fatores, da vontade de ir mais longe em busca da informação, utilizando criticamente o saber tecnológico na ação pedagógica, aventurando-se no seu poder ilimitado muito além do uso de softwares, pois os jovens estão prontos para usar todos os meios inovadores. E para que isso aconteça, é preciso contar com um professor multiplicador de saberes, hábil na mediação da diversidade do nosso sistema educacional, aproximando a si mesmo e a seus alunos do mundo digital e das novas linguagens, favorecendo o posicionamento crítico e participativo diante da atual sociedade.

Os relatos de experiência no campo da informática na escola comprovam que a integração da tecnologia às salas de aula não se deve à determinação de leis, ou inclusão nos núcleos curriculares sob a hierarquia das disciplinas, e sim às ações que promovem a pesquisa, a troca, a cooperação, mediando encontros e confrontos na criação permanente. Dificilmente um indivíduo que navegue pela Internet não se depara com outras bases culturais e não se reconstrua, assumindo posições, tomando decisões. Se ontem o capital e o trabalho eram os pilares da sociedade, hoje o conhecimento é um patrimônio perene, mesmo que sujeito a mutações. O discurso do sistema educacional, pautado nos pressupostos das teorias construtivistas transpostos para Educação por teóricos como Coll (1998), Zabala (1998), Carretero (1998), Delval (1998) entre tantos outros, enfatiza a importância da formação do aluno autônomo, capaz de aprender a aprender, de buscar e selecionar informações, de resolver problemas, ter agilidade mental e de ação, flexibilidade e coerência. Este perfil de aluno aponta um cidadão capaz de atuar em uma realidade que se estabelece progressivamente, fazendo consolidar novas formas de relação e produção, novas formas de viver e de ser profissional. Seu processo criativo (e crítico) pode tomar maior dimensão através da escola e do papel mediador e estimulador dos professores.

Mas dificilmente a escola tem um corpo docente integralmente despido de preconceitos quanto ao novo, à mudança, mostrando-se receptivo e preparado para perceber e assimilar os fatos tecnológicos, sociais e culturais mais amplos que seu mundo imediato, articulando-os aos métodos de ensino e aprendizagem com seus alunos. Uma aluna do $3^{\circ}$ ano do Ensino Médio da escola pública observada denuncia que, apesar do bem equipado laboratório de informática e da disponibilidade do projetor multimídia, todas as suas aulas são expositivas em salas convencionais. Os professores até sugerem a 
consulta na internet para os trabalhos extraclasse, tornando comum aos alunos frequentarem o laboratório em outro turno para realizar o dever de casa digitado (muitas vezes copiado), limitando aí a relação da informática com a disciplina. Tais procedimentos se contrapõem a quase totalidade do corpo docente possuidora de, pelo menos, celular, computador pessoal e, alguns, também de tablet ou Ipad, além do consenso de que o atual modelo pedagógico, pautado na aula expositiva, quadro de giz e livros didáticos é insuficiente para atender às muitas dúvidas e questões levadas à sala de aula, especialmente, pelos alunos que estão se preparando para concluir esta etapa de suas vidas. Outro exemplo na mesma escola, relatado por uma aluna do $5^{\circ}$ ano do Ensino Fundamental, reforça a dúvida se a subutilização dos recursos dos computadores por parte dos professores ocorre por desconhecimento do potencial dos equipamentos ou de elaboração de planos de aula que envolva técnicas midiáticas. Ela confirma ter aula de Língua Portuguesa e de Estudos Sociais no laboratório de informática instalado em seu segmento, mas são poucas as vezes em que as professoras das disciplinas permanecem no laboratório junto com a professora de informática, ficando esta última como mera "monitora" da execução da tarefa.

Em qualquer época ou lugar, os alunos deverão formar-se e educar-se para a vida e para o trabalho e, portanto, a escola precisará contar sempre com os professores para realizar tal tarefa. Mas como está o saber e o fazer pedagógico do professor hoje, diante da sua realidade de sala de aula? Que perfil profissional o professor precisa desenvolver para que ele possa dar conta das demandas da nova sociedade? Deve haver, entretanto, razões que impedem que a prática didática inclua meios modernos e eficazes, lúdicos até, coerentes com a forma de aprender da "Geração Next" ou "Geração Z”, segundo a classificação de Tapscott $(2010)^{2}$.

\section{O educador no século XXI}

Quando o homem, no seu processo sócio-histórico, transforma as formas de se comunicar, produzir e reproduzir no seu cotidiano, também transforma suas relações humanas e com a natureza. "Quando na nossa história coincidem três tipos de mudança - a descoberta de novas fontes energéticas, uma nova divisão do trabalho e uma nova organização de poder - estamos diante de um salto de época" (MASI, 2000, p.41).

Castells (1999) define uma diferença esclarecedora no que chama mão-de-obra genérica (a que possui a capacidade de recepção e execução limitada, quanto à incorporação de novas informações e a capacidade de se reprogramar para novas ações) e mão-de-obra autoprogramável (a que desenvolve a capacidade para redefinir suas tarefas diante do processo produtivo em constante mudança), designando a capacidade de atingir uma educação com qualidade o elemento crucial dessa diferenciação. $O$ novo perfil profissional coloca em evidência o papel da Educação como elemento-chave na construção dessa sociedade baseada na informação, no conhecimento e no aprendizado. Sob tal perspectiva, o professor necessita urgentemente tornar-se o mediador das experiências, saberes e opiniões, livrando-se das crenças antigas em que ele era o centro do conhecimento.

\footnotetext{
2 Tapscott (2010) classifica as gerações como Baby Boom os nascidos entre janeiro de 1946 a dezembro de 1964; Geração X, os nascidos em janeiro de 1965 a dezembro de 1976; Geração Internet, os nascidos entre janeiro de 1977 a dezembro de 1997, também chamados de Geração do Milênio ou Geração Y; e de Geração Next ou Geração Z aqueles que nasceram em janeiro de 1998 até o momento presente.
} 
Compreende-se quão difícil é para um adulto mudar suas atitudes e convicções, cristalizadas ao longo dos anos, entretanto, a sociedade tecnológica, estruturalmente competitiva e veloz, tende a ser cada vez menos tolerante com o indivíduo que se mantém hermeticamente fechado em suas próprias experiências e conhecimentos. Por sua vez, os PCNs do Ensino Médio (MEC, 1999) dispõem artigos de capacitação contínua para os profissionais da educação (Título VI), desconsiderando a cruel realidade do aluno-professor, que precisa cumprir longas jornadas de trabalho e, não raro, conjugá-las a outras atividades para compor uma renda salarial digna, sem tempo ou oportunidade de conhecer outras literaturas, novas mídias, trocar ideias, experimentar novas metodologias. Dessa maneira, ele recebe determinação de leis, manuais, apostilas, programas de ensino, sem tempo de entender e menos ainda sem oportunidade de (auto) avaliar o método de trabalho.

Sem pretensão de avaliar a formação do professor, sabe-se que ele a conclui como aprendizagem definitiva, de acordo com a cultura acadêmica do país. O incentivo à pesquisa e ou à aprendizagem contínua é pouco ou nunca estimulado, a menos que sua trajetória profissional inclua outros anseios e expectativas além da sala de aula. Nesse contexto, a escola reúne um grupo de especialistas que, dependendo do seu grau social e cultural, vão se relacionar com a informação e a tecnologia de forma ativa ou passiva. Isso é visível nos universitários, licenciandos nas escolas de educação básica, que se submetem a estágios regidos por planos de trabalho obsoletos e sem sentido, sem qualquer referência ao uso de tecnologias no cotidiano escolar. Essa atitude passiva surpreende, considerando que esses jovens aspirantes a educadores pertencem à Geração Internet (TAPSCOTT, 2010), profundamente familiarizados com o uso de quase todos os artefatos digitais.

Para Perrenoud, Paquay, Altet e Charlier (2001), os educadores precisam desenvolver competências básicas para que possam construir um trabalho efetivamente profissional, baseado em conhecimentos teóricos (disciplinares, culturais, pedagógicos e didáticos) e práticos (experiência, modalidade e postura). Zabala (1998, p.10) define "os professores, independente do nível em que trabalhem, como profissionais que devem diagnosticar o contexto de trabalho, tomar decisões, atuar e avaliar a pertinência das atuações, a fim de reconduzi-las no sentido adequado". O uso das TI na Educação refere-se a todas as ferramentas intelectuais, sociais e materiais à disposição do planejamento, da prática e da avaliação do ensino e da aprendizagem, reforçando que as possibilidades de mudanças são infinitas e desafiadoras nos processos educacionais.

A realidade do professor brasileiro ainda é marcadamente analógica e a proposta de ensino, na maioria das situações, valida a memorização, a reprodução e a transmissão de informações e os recursos didáticos utilizados se submetem a esse contexto, estabelecendo uma relação pouco interativa e limitada na abordagem desses materiais. Pensar na (re)profissionalização do professor em direção à nova cultura do trabalho consiste em vê-lo primeiro como aprendente, ou seja, saber como está "conectado" ao mundo e como se apropria da sua realidade, da sua cultura. É relevante também constatar se o professor é capaz de construir procedimentos para "acessar" informações, de aprender a aprender, além de investir na ampliação das suas concepções, não as definindo como verdades acabadas e definitivas. Injusta ou não, esta situação não retrocederá jamais. 


\section{A escola no século XXI}

Mesmo com política e economia sinuosas, o Brasil emprega esforços na inclusão digital de sua população, levando computadores ligados em rede a todo tipo de instituição, enfrentando muitos desafios, especialmente, para implantar física e politicamente a informática em suas redes de ensino. A Secretaria de Educação a Distância - SEED, do Ministério da Educação do Brasil, elaborou, em 1996, o Programa Nacional de Informática na Educação - $\mathrm{PROINFO}^{3}$, que desenvolvido em parceria com os governos estaduais e municipais, visava introduzir a telemática nas escolas públicas de todo o país, com o objetivo de melhorar a qualidade do processo de ensino e aprendizagem de forma a preparar o aluno para o exercício da cidadania. O Programa iniciou equipando seis mil das, aproximadamente, duzentas mil escolas públicas de ensino básico de todo o país, com cem mil computadores, reservando mais cinco mil para os Núcleos Tecnológicos de Educação - NTE, responsáveis pela capacitação dos professores.

Passados 20 anos, as políticas públicas de Educação continuam investindo na integração das TI nas escolas, sob novas políticas pouco definidas, para introduzir o computador e "convidar" o professor a se conectar. Por sua vez, os setores das universidades dedicados ao tema avançam muito nas pesquisas e experimentos, contribuindo com um bom impulso na oferta de cursos de formação continuada e de capacitação profissional presenciais e à distância, tanto em instituições públicas quanto privadas (CAMPOS, CAMPOS, ROCHA, 1999).

Mas ao que parece, a escola mostra-se reticente diante das tecnologias, menos por não tê-las e mais por não entendê-las. Sabe-se que alguns diretores de estabelecimentos de ensino, com laboratórios de informática e outros equipamentos para uso didáticopedagógico, exigem que este espaço seja trancado a fim de que "ninguém possa estragálo". Essa atitude dilui as pontuais iniciativas de uns poucos professores desejosos de fazer uma escola conectada ao mundo.

A escola pública tomada como referência neste trabalho possui, pelo menos, um laboratório de informática em cada campus, atualizado a cada dois anos, com uma média de 25 computadores e 1 impressora. Há quatro anos foram adquiridos quadros interativos para todos os campi, mas somente 2 foram instalados e estão sendo usados por dois professores de Informática. O funcionamento deste espaço depende de um ou dois professores, um auxiliar administrativo e um auxiliar técnico, total insuficiente para cobrir os dois ou três turnos dos campi. Os professores de Informática têm carga horária distribuída em três dias fixos da semana ${ }^{4}$ para atender basicamente as turmas de $6^{\circ}$ e $7^{\circ}$ anos, desenvolvendo projetos livres, eventualmente, de algum tema do currículo. A produção pedagógica desse grupo é relevante e significativa para justificar a presença da matéria no programa curricular, mas mesmo realizada com êxito, não conta com continuidade, como foi o caso de um blog desenvolvido especificamente para apoio aos alunos que precisavam ser nivelados em Educação Musical.

\footnotetext{
${ }^{3}$ O PROINFO foi proposto pelo governo em novembro de 1996 e iniciado em 1997, para levar computadores e Internet às salas de aula. Atualmente, sob outro nome, pretende fomentar a EAD no país em vários níveis de ensino. (www.proinfo.org.br)

${ }^{4}$ A estrutura desta escola tem as disciplinas funcionando em dias fixos pares ou impares da semana. Por exemplo, as disciplinas de Línguas Portuguesa e estrangeiras, Matemática, Química, Música acontecem somente às $2^{\text {as }}, 4^{\text {as }}$, e $6^{\text {as }}$ feiras, enquanto que História, Geografia, Ciências, Artes, Sociologia, Filosofia e Informática acontecem às $3^{\text {as }}, 5^{\text {as }}$ e sábados.
} 
De qualquer forma, com ou sem infraestrutura suficiente, os dirigentes das escolas precisam aceitar o desafio de formar equipes aptas em tecnologia, ainda que, numa primeira etapa, sacrifique algumas horas de aulas em benefício do investimento na sua (re)profissionalização. Em contra partida, formam-se professores mais preparados e sintonizados com a modernidade. Quaisquer que sejam as propostas, a escola deve, urgentemente, instrumentalizar-se para conhecer a si mesma e poder definir projeções compatíveis com a sua comunidade. A atual Geração Internet (TAPSCOTT, 2010) de educadores precisa conscientizar-se de que a educação do modo como a conheceu é obsoleta, incapaz de oferecer à Geração Next (Ibdem) que frequenta a escola agora, com acesso a quase todo tipo de tecnologia fora do ambiente escolar, caminhos que conduzam a soluções.

\section{Considerações parciais}

A história das reformas educacionais no Brasil registra planejamentos centrados nos conteúdos a serem trabalhados, visando basicamente ao desenvolvimento do perfil do "novo" aluno, supostamente preparando-o para ingressar no mundo do trabalho, investindo quase nada nos educadores que estão na linha de frente para cumprir as últimas determinações. Cada proposta educativa com informática continua sendo um desafio: os alunos chegam mais "sabidos" quanto aos recursos dos computadores e com interesses próprios de navegação, longe de qualquer questionamento; os professores atuam sem motivação para fazer algo diferente e a situação é agravada pelo excesso de burocracia escolar. Há também o mito de que trabalhar no laboratório de informática significa ir além das suas horas de aula. Contudo, quem já desenvolveu alguma atividade nesse ambiente sabe que o atendimento ao aluno é quase individualizado, que o volume de trabalhos para corrigir não é diferente do volume produzido nas aulas regulares, como descobre também que, ao se envolver em uma atividade cooperativa ou colaborativa na web, dificilmente será o mesmo cidadão.

O criar está inserido na possibilidade de pensar diferente, de inovar, de lidar com a diversidade social e cultural. Assim, o que cabe ao professor na sua relação com o aluno nesse momento de transformação numa perspectiva diferenciada da Educação precisa ser redimensionado. $O$ professor, mais que qualquer outro cidadão, tem que estar engajado nesta proposta de vida e de transformação, pois ele tem a responsabilidade de orientar a construção de pontes entre os saberes dos estudantes e a Escola, como parte integrante dessa sociedade, cujos referenciais têm se alterado, não pode ignorar esse processo, pois é responsável pela formação do aluno enquanto cidadão que deverá pertencer, ativamente, à dinâmica dessa sociedade.

O computador e a Internet como ferramentas das TI, com todo o seu potencial de interatividade são recursos tecnológicos que, se bem utilizados, podem levar a princípios e habilidades que ajudarão o professor em novas aprendizagens. Dar um sentido educacional à tecnologia significa tratá-la como um conjunto de ferramentas físicas, simbólicas, sociais e organizadoras, a serviço de um saber (conceitual e/ou informacional) e de um saber-fazer (procedimental e estratégico) que propiciará a construção de conhecimentos e de novas aprendizagens. Considerando uma larga escala que se estende do mundo analógico ao virtual, a entrada da tecnologia na educação é promissora, a depender das oportunidades do professor para conectar-se e interagir em uma rede de conhecimentos, validando seu saber e fazer, ou seja, sua competência 
profissional. Partindo dessa premissa, recomendam-se algumas ações que indicam fazer emergir a informática educativa: (a) estruturar o plano de aulas, de modo a ter todas as turmas de todos os anos atendidos no laboratório de informática ao longo do ano; (b) incentivar a criação de acervo de trabalhos bem sucedidos em parceria com outras disciplinas; (c) incentivar a utilização de objetos de aprendizagem (disponíveis no RIVED $^{5}$ ); (d) divulgar os resultados o mais amplamente possível, dentro e fora da escola; (e) estimular a oferta de cursos de capacitação na área; e (f) incentivar a participação em redes sociais.

$\mathrm{O}$ argumento aqui apresentado pretende contribuir para o avanço das discussões acerca da insuficiência de professores que atuam na sala de aula com espírito interdisciplinar, versátil, irrestrito a outros saberes além dos específicos e, mais importante, um observador crítico das questões socioculturais, que seja capaz de exercer sua profissão utilizando as TI como meio de retroalimentação do conhecimento.

Conforme pode ser constatado neste trabalho, o computador na escola por si só não provoca mudanças. Com efeito, o computador reproduz o modelo pedagógico tradicional, servindo como uma prolongação do lápis e, quando possível, como um apoio para transmitir informação, confinados em laboratórios de informática. Ensinar e aprender não se resumem a uma determinação política, é, sobretudo, uma vontade pessoal, individual e este sentimento está acima do conteúdo que se precisa apreender. Ainda hoje as escolas têm toda a sorte de dificuldades para capacitar seus professores em Informática. Revendo o que já se investiu, constata-se que não se limita a falta de metodologia ou erro de estratégia, mas sim da própria cultura em assimilar o potencial dos equipamentos digitais. Espera-se que isso seja gradativamente superado pelas próximas gerações de educadores.

\section{Referências Bibliográficas}

ALTET, M. "As competências do professor profissional: entre conhecimentos, esquemas de ação e adaptação, saber analisar". In: Perrenoud, P., Paquay, L., Altet, M. E Charlier, E. (orgs.). Formando professores profissionais. Quais estratégias?Quais competências? Porto Alegre: Artmed, 2001, p.23-35.

ANDRADE, Pedro Ferreira. Modelo Brasileiro de Informática na Educação. Disponível em: http://www.c5.cl/ieinvestiga/actas/ribie96/43.html. Acesso em 15/07/2013

AREA, M. in SANCHO, J.M.; HERNÁNDEZ, F.(orgs). Tecnologias para transformar a educação. Porto Alegre: Artmed, 2008.

CAMPOS, F. C. A.; CAMPOS, G. H. B.; ROCHA, A. R. C. Tradicionalismo x Inovação: a informática educativa nas escolas brasileiras. In Anais do V Workshop de Informática na Escola, pp. 613-625. PUC-Rio, RJ, 19-21de julho de 1999.

CARRETERO, M. e LIMÒN, M. Problemas atuais do construtivismo: da teoria à prática. In: RODRIGO, M.J. e ARNAY, J (orgs). Conhecimento Cotidiano, escolar e científico: representação e mudança. São Paulo: Editora Ática, 1998.

CASTELLS, M. A Era da Informação: economia, sociedade e cultura, vol. 3, São Paulo: Paz e Terra, 1999.

\footnotetext{
${ }^{5}$ RIVED - Rede Interativa Virtual de Educação. Disponível em ttp://rived.mec.gov.br/site_objeto_lis.php
} 
CATASÚS, M. G. Multimèdia i comunicació a la Universidade Oberta de Catalanya. Catalunya: UOC. 1996.

COLL, C. Psicologia e Currículo - uma aproximação psicopedagógica à elaboração do currículo escolar. São Paulo: Editora Ática, 1998.

DEVAL, J. “Teses sobre o Construtivismo". In: RODRIGO, M.J. e ARNAY, J (orgs). Conhecimento Cotidiano, escolar e científico: representação e mudança. São Paulo: Editora Ática, 1998.

JORNAL DA CIÊNCIA (JC E-Mail). MEC anuncia projetos para formação de docente. - Notícias de C\&T - No. 1675- Serviço da SBPC. 28/novembro/2000

MASI, D. de. O ócio criativo. Rio de Janeiro: Sextante. 2000.

MINISTÉRIO DA EDUCAÇÃO. Proposta de diretrizes para a formação inicial de professores da educação básica, em curso de nível superior. Brasília: MEC. Maio de 2000.

MINISTÉRIO DA EDUCAÇÃO. Parâmetros Curriculares Nacionais: ensino médio: bases legais/MEC. Brasília: MEC/Secretaria de Educação Média e Tecnológica, 1999.

MORAES, M. C. (1997). Informática Educativa no Brasil: Uma história vivida, algumas lições aprendidas. Disponível em: http://www.edutecnet.com.br/Textos/Alia/MISC/edmcand1.html. Acesso em: 15/07/2013.

MOULIN, S. I. L.; RAABE, A. Novas Tecnologias n Educação: Transformações da Prática Pedagógica no Discurso Do Professor. Anais do $18^{\circ}$ Workshop de Informática na Escola. WIE 2012. ISSN 2316-65410. Disponível em: http://www.brie.org/pub/index.php/wie/article/view/2104 Acesso em: 17/07/2013.

PERRENOUD, P. "Formar professores em contextos sociais em mudança". Revista Brasileira da Educação. N. 12. set/out/nov/dez, 1999.

PRETTO, N.de L. Desafios para a educação na era da informação: o presencial, a distância, as mesmas políticas e o de sempre. In: Tecnologias educacionais e educação a distância: avaliando políticas e práticas. Rio de Janeiro: Quartet Editora, 2001.

SAMPAIO, M. N. e LEITE, L. S. Alfabetização tecnológica do professor. Petrópolis: Editora Vozes. 2001

SANCHO, J.M.; HERNÁNDEZ, F. Tecnologias para transformar a educação. Porto Alegre: Artmed. 2008.

TAPSCOTT, D. A hora da geração digital. Rio de Janeiro: Agir Negócios, 2010.

ZABALA, A. A Prática Educativa - como ensinar. Porto Alegre: Artmed,1998. 